\title{
Advancement in navigational path planning of robots using various artificial and computing techniques
}

\begin{abstract}
In this paper, a review analysis has been carried out on navigational methodologies of robots with the help of various artificial intelligence techniques such as Fuzzy Logic, Neural Network, Genetic Algorithm, Particle Swarm Optimisation (PSO) and other Artificial Intelligence techniques. During the survey analysis a systematic review has been done and shown how various artificial intelligence techniques can be successfully used for control and navigation of various types of robots subjected to various environmental conditions.
\end{abstract}

Volume 4 Issue 2 - 2018

\author{
Dayal R Parhi \\ Department of Mechanical Engineering, N.I.T. Rourkela, India
}

Correspondence: Dayal R Parhi, Department of Mechanical Engineering, N.I.T. Rourkela, India, Email dayaldoc@yahoo.com

Received: February 28, 2018 | Published: April II, 2018

Keywords: fuzzy, neural, genetic, PSO, artificial intelligence

\section{Introduction}

For decades several papers have been written on control and navigation of robots using artificial intelligent techniques such as fuzzy logic, neural network, genetic technique and other artificial intelligence techniques. Monitel \& Adriansyah et al. ${ }^{1,2}$ have discussed about use of fuzzy logic techniques for control and navigation of mobile robot. Jin \& Zuo et al. ${ }^{3,4}$ have analysed neural network techniques for control of mobile robot. Sheng and $\mathrm{Li}^{5}$ have used genetic algorithm for trajectory control of robot. Mohamed et al. ${ }^{6}$ have used potential field method for optimisation of path followed by an unmanned vehicle from source position to target position. Abdalla et al. ${ }^{7}$ have used particle swarm optimisation technique to find a safer path for mobile robot during navigation. Various researchers have used several techniques for finding out collision free path for robots.

\section{Analysis of various ai techniques used for navigation}

Yunong et al. ${ }^{8}$ have discussed about Ubiquitous Robots using Ambient Intelligence. They have achieved the balancing of a robot using fuzzy controller. Rainer et al. ${ }^{9}$ have used fuzzy logic for decision making of an autonomous guide-robot. They have shown that the robot can interact with human and fuzzy logic is used to take the suitable decision. Nasrinahar and Chuah ${ }^{10}$ have discussed about safe navigation of robot using fuzzy intelligent technique. They have used four behaviour controllers, which are taken care by the fuzzy logic during navigation. To solve these problems, an improved Q-learning algorithm based on a bioinspired neural network (BNN) is proposed for robot path planning in this paper. $\mathrm{Ni}$ et al. ${ }^{11}$ have used bio inspired neural network (BNN) with $\mathrm{Q}$ learning technique for path planning of robot in an unknown environment. Long and $\mathrm{Nan}^{12}$ used Fuzzy Wavelet Neural Networks method for control and tracking of non Holonomic mobile manipulator robot. Alouache \& Choi and Park ${ }^{13,14}$ have used Lyapunov criteria and Genetic Algorithms (GA) to optimize the gains of the controller trajectory tracking for mobile robot. Kato et al..$^{15}$ in their paper have discussed about the GAIT pattern of robot while moving. Shukla ${ }^{16}$ has discussed about exploration of area using robots with the help of Genetic Algorithm. Liu et al. ${ }^{17}$ have discussed about virtual potential filed method using reinforced learning method for path control of robot. Papers ${ }^{18-31}$ have discussed about the artificial intelligence method such as fuzzy logic, neural network and genetic algorithm for control of mobile robots and for application in other engineering fields. Ashourian et al. ${ }^{32}$ in their paper have discussed about control of motor like mobile robot using neural network and potential field method. Karaboga and kaya ${ }^{33}$ have discussed about ANFIS model for addressing optimisation problem. Control of a inverted pendulum using ANFIS has been discussed by Kharola and Patil. ${ }^{34}$ Huang et al. ${ }^{35}$ have analysed exoskeleton upper body control of a robot using ANFIS methodology. Papers ${ }^{36-45}$ discussed about cuckoo search method and other soft computing methods for path planning of robots in complex environments. Aziz Z\& Hassanien ${ }^{46}$ have discussed about feature selection using cuckoo search algorithm. Manikota et $\mathrm{al}^{47}$ have discussed about cuckoo search method for error minimisation and localisation of robot. Sheth et $\mathrm{al}^{48}$ have used soft computing technique using computer vision for AGV control. Vermesan et al ${ }^{49}$ have discussed about use of Internet in robotic control. $\mathrm{Li}$ and $\mathrm{Chou}^{50}$ have discussed about PSO for near optimal path planning of mobile robot in a complex environment. Papers ${ }^{51-54}$ focus on artificial immune system and other computing techniques for path analysis of mobile robot. Zamri et al. ${ }^{55}$ have discussed about gene expression data using swarm intelligence technique. Ravinandan et al. ${ }^{56}$ have discussed about path generation using cognitive map and swarm intelligence technique. Hong et al. ${ }^{57}$ have discussed about rule based fuzzy navigator with the help of scaling parameters for mobile robot. Mohanta et al. ${ }^{58}$ used genetic technique for navigation of mobile robot. Papers ${ }^{59-66}$ have discussed about differential evolutionary algorithm integrated with other techniques to address various engineering problems. In the papers ${ }^{67-71}$ neuro fuzzy technique for various engineering applications have been discussed. Singh et al., ${ }^{72-76}$ have used neural network and fuzzy logic for robots navigation in various environmental conditions. Pandey et al. ${ }^{77,78}$ have discussed about fuzzy logic and ANFIS method for control of robots subjected to various terrains. The paper ${ }^{79}$ has discussed about path planning using adaptive neuro-fuzzy inference system for mobile robot. Wavelet neural network for navigation of mobile robot has been discussed by Panigrahi et al ${ }^{80-82}$ have focused on adaptive neuro fuzzy technique for control of mobile robot. Pham et al ${ }^{83}$ have used neural network technique for path planning of mobile robots. Sorin et al. ${ }^{84}$ have discussed about safety challenges of robots during functional time of robots. 


\section{Conclusion}

In the current research review, analysis has been done on various Artificial Intelligence techniques for robotic navigation, control and path generation in complex environments. It is observed that the using methods such as Fuzzy, Neural, PSO, Cuckoo Search, Ant Colony, Artificial Immune System and other AI techniques, robots can successfully negotiate with obstacles while achieving the objectives in complex terrain conditions.

\section{Acknowledgements}

None.

\section{Conflict of interest}

The author declares there is no conflict of interest.

\section{References}

1. Montiel O, Sepúlveda R, Murcio I, et al. Geo-navigation for a mobile robot and obstacle avoidance using fuzzy controllers. In Recent advances on hybrid approaches for designing intelligent systems. Springer; 2014;547:647-669.

2. Adriansyah A, Amin SHM. Wall-following behavior-based mobile robot using particle swarm fuzzy controller. Journal Ilmu Komputer dan Informasi. 2016;9(1):9-16.

3. Jin L, Li S, Yu J, et al. Robot manipulator control using neural networks: A survey. Neurocomputing. 2018;285:23-34.

4. Zuo Y, Wang Y, Liu X. Adaptive robust control strategy for rhombustype lunar exploration wheeled mobile robot using wavelet transform and probabilistic neural network. Computational and Applied Mathematics. Springer; 2017:1-24.

5. Sheng L, Li W. Optimization design by genetic algorithm controller for trajectory control of a 3-rrr parallel robot. Algorithms. 2018;11(1):7.

6. Mohamed A, Ren J, Sharaf AM, et al. Optimal path planning for unmanned ground vehicles using potential field method and optimal control method. International Journal of Vehicle Performance. 2018;4(1):1-14.

7. Abdalla TY, Abed AA, Ahmed AA. Mobile robot navigation using PSOoptimized fuzzy artificial potential field with fuzzy control. Journal of Intelligent \& Fuzzy Systems. 2017;32(6):3893-3908.

8. Yunong Y, Ha HM, Kim YK, et al. Balancing and driving control of a ball robot using fuzzy control. In Ubiquitous Robots and Ambient Intelligence; $201512^{\text {th }}$ International Conference on Goyang, IEEE; 2015:492-494.

9. Rainer JJ, Cobos-Guzman S, Galán R. Decision making algorithm for an autonomous guide-robot using fuzzy logic. Journal of Ambient Intelligence and Humanized Computing. 2017;1-13.

10. Nasrinahar A, Chuah JH. Intelligent motion planning of a mobile robot with dynamic obstacle avoidance. Journal on Vehicle Routing Algorithms. 2018;1-16.

11. Ni J, Li X, Hua M, et al. Bio inspired neural network based q-learning approach for robot path planning in unknown environments. Int $J$ Robot Autom. 2016;31:4526-4590.

12. Long MT, Nan WY. Adaptive position tracking system and force control strategy for mobile robot manipulators using fuzzy wavelet neural networks. Journal of Intelligent \& Robotic Systems. 2015;79(2):175-195.

13. Alouache A, Wu Q. Tracking control of multiple mobile robot trajectory by genetic algorithms. Electrotehnica, Electronica, Automatica. 2017;65(4):155-161.
14. Choi YK, Park JH. Control gain optimization for mobile robots using neural networks and genetic algorithms. Journal of the Korea Institute of Information and Communication Engineering. 2016;20(4):698-706.

15. Kato T, Shiromi K, Nagata M, et al. Gait pattern acquisition for fourlegged mobile robot by genetic algorithm. In Industrial Electronics Society, IECON; 2015-41st Annual Conference of the IEEE; 2015 November; 2015:004854-004857.

16. Shukla A. Improved approach to area exploration in an unknown environment by mobile robot using genetic algorithm, real time reinforcement learning and co-operation among the controllers. In Advances in Control and Optimization of Dynamical Systems. 2014;3(1):155-158.

17. Liu J, Qi W, Lu X. Multi-step reinforcement learning algorithm of mobile robot path planning based on virtual potential field. In International Conference of Pioneering Computer Scientists, Engineers and Educators; Singapore: Springer; 2017:528-538.

18. Parhi DR, Singh MK. Intelligent fuzzy interface technique for the control of an autonomous mobile robot. Journal of Mechanical Engineering Science. 2008;222(11):2281-2292.

19. Parhi DR, Pradhan SK, Panda AK, et al. The stable and precise motion control for multiple mobile robots. Applied Soft Computing. 2009;9(2):477-487.

20. Parhi DR, Behera AK Dynamic deflection of a cracked beam with moving mass. Journal of Mechanical Engineering Science. 1997;211(1):77-87.

21. Parhi DR, Singh MK. Real- time navigational control of mobile robots using an artificial neural network. Journal of Mechanical Engineering Science. 2009;223(7):1713-1725.

22. Parhi DR, Mohanta JC Navigational control of several mobile robotic agents using Petri-potential-fuzzy hybrid controller. Applied Soft Computing. 11(4):3546-3557.

23. Parhi DR, Behera AK. Dynamic deflection of a cracked shaft subjected to moving mass. Canadian Society for Mechanical Engineering, Transactions. 1997;21(3):295-316.

24. Parhi DR, Pothal JK, Singh MK. Navigation of multiple mobile robots using swarm intelligence. In Nature \& Biologically Inspired Computing, 2009. NaBIC 2009. World Congress, IEEE; 2009 December; 2009:11451149

25. Parhi D.R, Choudhury S. Smart crack detection of a cracked cantilever beam using fuzzy logic technology with hybrid membership functions. Journal of Engineering and Technology Research. 2011;3(8):270-278.

26. Parhi DR, Dash AK. Application of neural network and finite element for condition monitoring of structures. Journal of Mechanical Engineering Science. 2011;225(6):1329-1339.

27. Parhi DR, Singh MK. Navigational strategies of mobile robots: a review. International Journal of Automation and Control. 2009;3(2-3):114-134.

28. Parhi DR, Choudhury S. Analysis of smart crack detection methodologies in various structures. Journal of Engineering and Technology Research. 2011;3(5):139-147

29. Parhi DRK, Kumar DA. Analysis of methodologies applied for diagnosis of fault in vibrating structures. International Journal of Vehicle Noise and Vibration. 2009;5(4):271-286.

30. Parhi DRK, Dash AK. Faults detection by finite element analysis of a multi cracked beam using vibration signatures. International Journal of Vehicle Noise and Vibration. 2010;6(1):40-54.

31. Parhi DR, Pothal JK. Intelligent navigation of multiple mobile robotsusing an ant colony optimization techniquein a highly cluttered environment. Journal of Mechanical Engineering Science. 2011;225(1):225-232. 
32. Ashourian M, Rastegari M J, Monadjemi A. Navigation of a mobile robot using a virtual potential field and artificial neural network. Journal of Artificial Intelligence in Electrical Engineering. 2016;5(17);11-20.

33. Karaboga D, Kaya E. Adaptive network based fuzzy inference system (ANFIS) training approaches: a comprehensive survey. Artificial Intelligence Review. 2018:1-31.

34. Kharola A, Patil P. A PID based ANFIS control of inverted pendulum climbing on inclined plane. Nonlinear Studies. 2017;24(1).

35. Huang JB, Young KY, Ko CH. Effective control for an upper-body exoskeleton robot using ANFIS. In System Science and Engineering (ICSSE); 2016:1-4.

36. Mohanty PK, Parhi DR. Cuckoo search algorithm for the mobile robot navigation. In International Conference on Swarm, Evolutionary, and Memetic Computing. Springer; 2013:527-536.

37. Mohanty PK, Parhi DR. A new intelligent motion planning for mobile robot navigation using multiple adaptive neuro- fuzzy inference system. Applied Mathematics \& Information Sciences. 2014;8(5):2527-2535.

38. Mohanty PK, Parhi DR. Navigation of autonomous mobile robot using adaptive network based fuzzy inference system. Journal of Mechanical Science and Technology. 2014;28(7):2861-2868.

39. Mohanty PK, Parhi DR, Jha AK, et al. Path planning of an autonomous mobile robot using adaptive network based fuzzy controller. In Advance Computing Conference (IACC), 2013 IEEE $3^{\text {rd }}$ International; 2013:651656.

40. Mohanty JR, Verma BB, Ray PK, et al. Application of artificial neural network for fatigue life prediction under interspersed mode-I spike overload. Journal of Testing and Evaluation. 2009;38(2):177-187.

41. Mohanty PK, Parhi DR. Optimal path planning for a mobile robot using cuckoo search algorithm. Journal of Experimental \& Theoretical Artificial Intelligence. 2016;28(1-2):35-52.

42. Mohanty PK, Parhi DR. Path planning strategy for mobile robot navigation using MANFIS controller. In Proceedings of the International Conference on Frontiers of Intelligent Computing: Theory and Applications (FICTA)2013; Springer; 2014:353-361.

43. Mohanty PK, Parhi DR. A new hybrid optimization algorithm for multiple mobile robots navigation based on the CS-ANFIS approach. Memetic Computing. 2015;7(4):255-273.

44. Mohanty PK, Parhi DR. A new efficient optimal path planner for mobile robot based on Invasive Weed Optimization algorithm. Frontiers of Mechanical Engineering. 2014;9(4):317-330.

45. Mohanty PK, Parhi DR. Navigation of an autonomous mobile robot using intelligent hybrid technique. In Advanced Communication Control and Computing Technologies (ICACCCT), IEEE; 2012:136-140.

46. El Aziz MA, Hassanien AE. Modified cuckoo search algorithm with rough sets for feature selection. Neural Computing and Applications. 2018;29(4):925-934.

47. Mankotia D, Agrawal S, Singh S. Error minimization in bluetooth based indoor localization of a mobile robot using cuckoo search algorithm. In Medical Imaging, m-Health and Emerging Communication Systems (MedCom), 2014 International Conference IEEE 2014:283-288.

48. Sheth S, Ajmera A, Sharma A, et al. Design and Development of Intelligent AGV Using Computer Vision and Artificial Intelligence. In Soft Computing: Theories and Applications; Singapore, Springer; 2018:337-349.

49. Vermesan $\mathrm{O}$, Bröring $\mathrm{A}$, Tragos $\mathrm{E}$, et al. Internet of robotic things: converging sensing/actuating, hypo connectivity, artificial intelligence and IoT Platforms. Cognitive Hyperconnected Digital Transformation: Internet of Things Intelligence Evolution; 2017:97-155.

50. Li G, Chou W. Path planning for mobile robot using self-adaptive learning particle swarm optimization. Science China Information Sciences. 2018;61(5):052204.

51. Deepak BBVL, Parhi DR, Kundu S. Innate immune based path planner of an autonomous mobile robot. Procedia Engineering. 2012;38:2663-2671.

52. Deepak BBVL, Parhi DR. Control of an automated mobile manipulator using artificial immune system. Journal of Experimental \& Theoretical Artificial Intelligence. 2016;28(1-2):417-439.

53. Deepak BBVL, Parhi DR. Target seeking behaviour of an intelligent mobile robot using advanced particle swarm optimization. In Control, Automation, Robotics and Embedded Systems (CARE), 2013 International Conference IEEE; 2013:1-6.

54. Deepak BBVL, Parhi DR. Kinematic analysis of wheeled mobile robot. Automation \& Systems Engineering. 2011;5(2).

55. Zamri NA, Thangavel B, Ab Aziz NA, et al. Review on the usage of swarm intelligence in gene expression data. In International Conference for Innovation in Biomedical Engineering and Life Sciences, Singapore, Springer; 2017:153-160.

56. Ravinandan ME, Prasad EV, Kumar MV. Adaptive path exploration and cognitive map generation using swarm intelligence. In Electrical, Electronics, Communication, Computer and Optimization Techniques (ICEECCOT), IEEE; 2016:318-321.

57. Hong C, Park CW, Kim JH. Evolutionary dual rule-based fuzzy path planner for omnidirectional mobile robot. In Fuzzy Systems (FUZZIEEE); 2016:767-774.

58. Mohanta JC, Parhi DR, Patel SK. Path planning strategy for autonomous mobile robot navigation using Petri- GA optimisation. Computers \& Electrical Engineering. 2011;37(6):1058-1070.

59. Behera RK, Pandey A, Parhi DR. Numerical and experimental verification of a method for prognosis of inclined edge crack in cantilever beam based on synthesis of mode shapes. Procedia Technology. 2014;14:67-74.

60. Behera RK, Parhi DR, Sahu SK. Vibration analysis of a cracked rotor surrounded by viscous liquid. Journal of Vibration and Control. 2006;12(5):465-494.

61. Behera RK, Parhi DR, Sahu SK. Dynamic characteristics of a cantilever beam with transverse cracks. International journal of Acoustics and vibration. 2006;11(1):3-18.

62. Jena PK, Thatoi DN, Nanda J, et al. Effect of damage parameters on vibration signatures of a cantilever beam. Procedia Engineering. 2012;38:3318-3330.

63. Jena PK, Thatoi DN, Parhi DR. Differential evolution: an inverse approach for crack detection. Advances in Acoustics and Vibration. 2013;2103:1-10.

64. Jena PK, Parhi DR. A modified particle swarm optimization technique for crack detection in Cantilever Beams. Arabian Journal for Science and Engineering. 2015;40(11):3263-3272.

65. Jena PK, Parhi DR, Pohit G. Theoretical, Numerical (fem) and experimental analysis of composite cracked beams of different boundary conditions using vibration mode shape curvatures. International Journal of Engineering and technology. 2014;6:509-518.

66. Agarwalla DK, Parhi DR. Effect of crack on modal parameters of a cantilever beam subjected to vibration. Procedia Engineering. 2013;51:665-669. 
67. Das HC, Parhi DR. Application of neural network for fault diagnosis of cracked cantilever beam. In Nature \& Biologically Inspired Computing, NaBIC 2009; 2009:1303-1308

68. Das HC, Parhi DR. Fuzzy-neuro controler for smart fault detection of a beam. International Journal of Acoustics and Vibrations. 2009;14(2):7080

69. Dash A, Parhi D. Analysis of an intelligent hybrid system for fault diagnosis in cracked structure. Arabian Journal for Science \& Engineering. 2014;39(2):1337-1357.

70. Thatoi DN, Das HC, Parhi DR. Review of techniques for fault diagnosis in damaged structure and engineering system. Advances in Mechanical Engineering. 2012;4:327569.

71. Khan IA, Parhi DR. Finite element analysis of double cracked beam and its experimental validation. Procedia Engineering. 2013;51:703-708.

72. Singh MK, Parhi DR, Pothal JK. ANFIS approach for navigation of mobile robots. In Advances in Recent Technologies in Communication and Computing, 2009. ARTCom'09. International Conference IEEE; 2009:727-731.

73. Singh MK, Parhi DR. Path optimisation of a mobile robot using an artificial neural network controller. International Journal of Systems Science. 2011;42(1):107-120.

74. Kundu S, Parhi R, Deepak BBVL. Fuzzy-neuro based navigational strategy for mobile robot. International Journal of Scientific \& Engineering Research. 2012;3(6):1-6.

75. Kundu S, Parhi R. Navigation of underwater robot based on dynamically adaptive harmony search algorithm. Memetic Computing. 2016;8(2):125146.

76. Pradhan SK, Parhi DR, Panda AK. Motion control and navigation of multiple mobile robots for obstacle avoidance and target seeking: a rule-based neuro-fuzzy technique. Journal of Systems and Control Engineering. 2009;223(2):275-288.
77. Pandey A, Sonkar RK, Pandey KK, et al. Path planning navigation of mobile robot with obstacles avoidance using fuzzy logic controller. In Intelligent Systems and Control (ISCO), IEEE $8^{\text {th }}$ International Conference IEEE; 2014:39-41.

78. Pandey A, Parhi DR. MATLAB Simulation for Mobile Robot Navigation with Hurdles in Cluttered Environment Using Minimum Rule Based Fuzzy Logic Controller. Procedia Technology. 2014;14:28-34.

79. Parhi DR, Singh MK. Navigational path analysis of mobile robots using an adaptive neuro-fuzzy inference system controller in a dynamic environment. Journal of Mechanical Engineering Science. 2010;224(6):1369-1381.

80. Panigrahi PK, Ghosh S, Parhi DR. Navigation of autonomous mobile robot using different activation functions of wavelet neural network. Archives of Control Sciences. 2015;25(1):21-34.

81. Panigrahi PK, Ghosh S, Parhi DR. A novel intelligent mobile robot navigation technique for avoiding obstacles using RBF neural network. In Control, Instrumentation, Energy and Communication (CIEC), 2014 International Conference IEEE; 2014:1-6.

82. Pothal JK, Parhi DR. Navigation of multiple mobile robots in a highly clutter terrains using adaptive neuro-fuzzy inference system. Robotics and Autonomous Systems. 2015;72:48-58.

83. Pham DT, Parhi DR. Navigation of multiple mobile robots using a neural network and a Petri Net model. Robotica. 2003;21(1):79-93.

84. Sorin A, Morten L, Kjeld J, et al. Rule-based dynamic safety monitoring for mobile robots. Journal of Software Engineering In Robotics. 2016;7(1):120-141. 